\title{
An Assessment of Strategies for Cultural Heritage Management and Tourism Development in the Eyasi Basin, Northern Tanzania
}

\author{
Pastory Magayane Bushozi \\ Department of Archaeology and Heritage, University of Dar Es Salaam, Dar Es Salaam, Tanzania
}

\begin{abstract}
This paper assesses the manner in which a local community has been incorporated into the management and utilization of cultural heritage resources in the lake Eyasi basin, northern Tanzania, in order to reduce poverty. One of the most important programs used to encourage rural developments is the outlay of cultural tourism. Lake Eyasi region is one of the few regions in Tanzania with brilliant cultural heritage resources including archaeological sites and distinctive indigenous cultural traits that cannot be seen in other places across Eastern Africa. Archaeological records of this region exhibit the earliest evidence for hominin morphological change from archaic to modern humans. It is also coherent key development traits including complex lithic technologies and artistic imaginations as it is the case for all living people. Ethnographic research in the region sheds light on the living standards of a modern foraging community that has consistently relied on wildlife resources for several decades. Both archaeological and ethnographical aspects have made this region an enduring attraction for tourists to seek a unique experience and gain an appreciation for the past. Even though there are positive impacts of tourism on rural development, there are potential challenges that need immediate attention.
\end{abstract}

Key words: Cultural heritage, community development, tourism.

\section{Introduction}

The lake Eyasi basin refers to the territory that has been used by hunting and foraging communities from Middle Pleistocene to the present (Fig. 1). This cultural landscape hosts a 21 st century foraging community (Hadzabe) and it is culturally termed as the Hadzabeland, meaning the eco-space where socio-cultural and economic activities of the Hadzabe historically and habitually occurred [1]. Geomorphologically, this region is characterized by fault escarpments, crystalline Proterozoic and Archaean basement rock (gneiss, schist and granite) outcrops at the southern terminal of the East African Rift Valley System (EARVS) [2]. Bedrock is extensively exposed in most of the area with scattered alluvial deposits close to the water catchment areas. The climate is generally warm and dry with

Correspondent author: Pastory Magayane Bushozi, Ph.D., research fields: human evolution and paleo environment reconstruction. mean annual temperatures ranging from $25^{\circ} \mathrm{C}$ to $30^{\circ} \mathrm{C}$ and annual rainfall ranging from $300 \mathrm{~mm}$ to $600 \mathrm{~mm}$, most of it falling during the rainy seasons from March to May [1]. The vegetation is primarily composed of arboreal member of the Somalia-Maasai phytogeographic characterized by savannah grasslands, woodlands and deciduous bush as well as shrub lands [3]. These vegetation types overlap to form a semi-arid vegetation continuum that sustains a wide range of edible plant species and animals that supported existence of foraging communities for several decades.

Today, few foraging groups remain in the Eyasi basin in select refugia where edible plants and hunted prey are naturally abundant. Foraging people acquire nearly all of their food by hunting wild animals and gathering wild plant foods and honey. They move around their traditional landscape seasonally depending on the distribution and reliability of wild food resources. In lake Eyasi basin, the Hadzabe people 


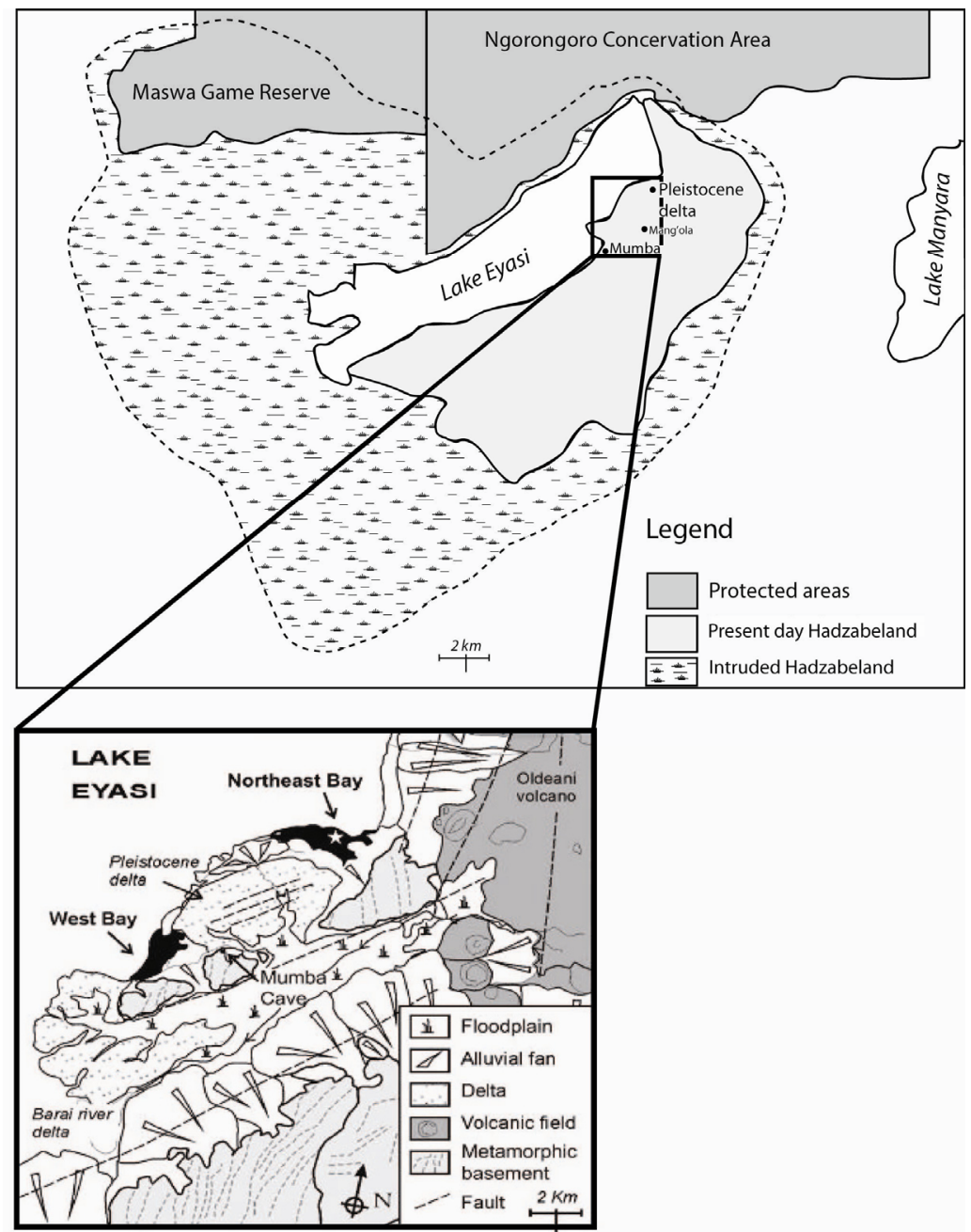

Fig. 1 Map of the lake Eyasi basin showing the past and present Hadzabe land in relation to the archaeological sites: Mumba rock-shelter as well as the Northeast (NEB) and West (WB) bays.

have coexisted with other ethnic groups including farmers and pastoralists for several centuries, but they have upheld their traditional foraging way of life to the present.

Tour operators, including the Tanzania Tourist Board (TTB), use Hadzabe lifestyle and practices to attract tourists who are encouraged to visit and gain first-hand experience of the foraging lifestyle including collection of wild plant roots, tubers, fruits, herbs, nuts and leaves for food as well as medicine. Tourists participate in collecting wild honey, extracting poisonous exudates, assembling poisoned arrowheads, hunting with bow and arrows, traditional dances and making fire. Other ethnographic attractions in the lake Eyasi basin include visits to
Datog (southern Nilotic pastoralists) Boma (homesteads) and other residential areas where tourists can get a glimpse of the Datog culture, including their use of traditional plants and medications along with their blacksmithing skills. Visitors can also spend time exploring popular onion farming activities and experience the traditional stockpiling of agricultural products [4]. In this paper, other cultural heritage resources of Eyasi basin region are evaluated in reference to the ambiguous tourism development programs.

Lake Eyasi like other regions in Tanzania, cultural tourism emerged as a community-based development strategy to alleviate poverty. Broadly, it aimed to engage local communities in their problems by selling 
their cultural products. It emerged after the 1980s global economic crisis that significantly affected the national economy. It was primarily initiated to address issues resulting from failed government plans for poverty eradication, increased human welfare and addressing disparities in economic gains $[5,6]$. In due regard, the Hadzabe and other ethnographical objects were constantly promoted and used to address potential socio-economic contests.

The 1980s economic crisis resulted from two main factors. First, the collapse of cash crop production including coffee, cotton, clove and tobacco in the international market; second, hostility, conflict and fighting with Idi Amin and former president of Uganda in late 1970s [7]. Such incidences led the country to experience economic calamity. As a result, many services and socio-economic facilities available to local communities (including health care, education and food) were limited.

One of attempts to improve welfare among rural communities involved promoting traditional values and allowing visitors to experience indigenous lifestyles, customs and local products. This strategy was designed to engage local people in solving their socio-economic problems and evade marginalization while preventing loss of workforce in rural areas [6]. It was also intended to reduce the magnitude of population influx in urban centers and retain the dignity and unique cultural practices of rural areas. Unfortunately, the lack of public services in rural areas still encouraged young people to move to urban centers for their socio-economic well-being [6]. To discourage this, most governments in developing countries introduced ambiguous rural development projects. Majority of them including the cultural tourism program lacked a clear focus and neglected other cultural attractions such as archaeological sites, museums, cultural landscape and historic towns. The focus of this approach was directed toward traditional arts and crafts, transforming traditional norms and values into commodities to meet the interests of tourists [6]. This system relied on community outreach programs. Tourists were able to experience traditional subsistence and economic practices such as hunting and gathering, farming, animal keeping, iron smelting, making handcrafts, eating traditional foods and brewing local beer. Tourists were also able to observe traditional dancing, traditional marriage procedures, religious plays, rain rituals and/or burial rites $[4,5]$.

One problem with the community outreach programs was lack of focus, as ethnographic tourism grew other cultural attractions such as archaeological and paleontological sites, historic towns and buildings, cultural landscapes, monuments and museums. In such arrangement, even famous and worldwide recognized cultural heritage sites like Olduvai Gorge and Laetoli were neglected, marginalized and not included in tourist packages. The place of cultural heritage resources in tourism development was badly informed and unclear to stakeholders, in particular, public and private institutions.

Another problem associated to such unclear cultural tourism development program is transforming forager's lifestyle into tourism products. Such approach made the Hadzabe people extremely useful not only to tourists, but also researchers interested in behavioral ecology, cultural evolutionary trends and other social aspects. The Hadzabe are among the most highly studied and visited communities and their life existence has become a focal point to test models related to behavioral ecology as well as cultural evolutionary trajectory. This was possible because the Hadzabe's lifestyle is completely different from most other living human populations. They live in band groups and move seasonally across the surrounding landscape, depending on seasonal distribution of wild food resources and availability of water. They use traditional tools, in particular, bow and iron tipped arrows for hunting and digging sticks for collecting tubers as well as hand held axes to acquire the beehive [8]. 
Largely, the Hadzabe have been negatively affected by a lack of government strategy concerning cultural tourism. Even though their way of life has made the area of lake Eyasi among the most famous tourism destinations in Tanzania, this minority group has never been appreciated by policy makers and tourism stakeholders. Even their cultural landscape is not legally protected, permitting intruders from neighboring communities and developers to grab their ancestral land (Fig. 1). One of the immediate effects of such arbitrary and uneven practice is sudden vanishing of the most dependable wild resources including edible plant and animal species. Some of the diminishing wild food resources can be associated with forest clearance, resulting from agricultural activities, unwarranted animal domestications and bucolic fuel consumption (charcoal and firewood). Such practices have altered the natural ecosystem setting of the region and the Hadzabe's living standards.

Globally, deforestation has been widely listed among key factors for ecological deteriorations and it has been named as a leading factor for loss of soil nutrients as well as inconsistence of the hydrological cycle and climatic conditions [7]. To local communities, such instability has greatly affected the living standards of rural communities in terms of efficiency of the cultural landscape in food production (due to unpredictable rainy seasons) and unreliability of drinkable water since both physical environment and cultural systems are inter-dependable entities [9, $10]$.

\section{Material and Methods}

Cultural heritage resources refer to tangible material remains and/or intangible customs, memories and rituals of societies, which embody their past activities and are transmitted from the past to the future generations $[11,12]$. In most cultures, the past is transformed into cultural heritage when the legacy of past-societies is re-evaluated, inherited and re-used by contemporary societies $[11,13,14]$. Therefore, cultural heritage resources are tangible materials and intangible customs from the past that are constantly appreciated as well as re-used by living communities to suit their present needs. In other words, they are used for economic gain, cultural identity, education, research, religious and other traditional activities $[13,15]$.

Human activity in the lake Eyasi basin can be traced back to when this landscape was inhabited by early ancestors around 300,000 years ago (ya). This is based on records of archaeological remains, extinct hominin species including early modern humans. These chronicles place this region into the unique position in the study of human biological and cultural evolution traits. Early research in this region was led by Ludwig and Margit Kohl-Larsen between 1933 and 1939 [16-18]. These research expeditions compiled important archaeological and paleontological records including homimin remains and collections representative of the history of how humankind evolved and dispersed across the planet. They also provided critical information on Stone Age archaeology, rock art and succession of subsistence patterns including technology from hunting and gathering to animal husbandry and farming. Other scholars working on the same region linked the past and present through detailed documentation of the Hadzabe who persist in the collection of wild food without farming $[4,19]$.

The plains near lake Eyasi shores, routinely termed as northeast and West bays, have been extensively surveyed and test excavated, resulting in documentation of multiple open-air sites (Fig. 1). Many of these localities are composed with human remains, lithic and fauna materials. In some places, they are still visible on the exposed sediments. Perhaps the best known specimen yielded from the open air sites near lake Eyasi is a heavily fossilized and well preserved cranium of a late archaic human $[16,17,20,21]$. Age estimates of the skull fall around 
250,000 ya, but preliminary Electron Spin Resonance (ESR) dating results from the fossiliferous bed outcrops suggest that it might be older than it was previously estimated. Hominin specimens of this region are very important because they represent the last known evolutionary stage from archaic to modern human morphological and cultural transformations in Africa.

Subsequent works along the lakeshore led to discovery of five more hominin remains, in particular, a cranium fragment and isolated teeth all represent a single species of archaic modern humans. In 2004, a frontal bone (EH 06) of an archaic human was retrieved from sedimentary deposits along the lakeshore and dated based on ESR to about 118,000 ya. But uranium series gives the age estimate of about 125,000 ya suggesting that archaic humans persisted in this region up to the Last Interglacial Maximum (LIM) [22]. Archaic and early modern humans from this region were found associated with Middle Stone Age (MSA) artifacts and fossil fauna of extinct as well as modern animal species [3, 18, 22]. Sediments from the lakeshore like other places across sub-Saharan Africa preserved paleoclimatic records which suggest the predominance of grassland, shrubs and riverine forests from the Middle Pleistocene to present [3, 10, 22].

At Mumba rock-shelter, the most notable excavations were carried out by several scholars from 1930s to present. From 1934 to 1938, Kohl and Margit Hansen exposed a huge excavation trench estimated to be about $1,000 \mathrm{~m}^{3}$ [20]. Samples collected from the 1930s excavations were shipped to Germany for further study where they are still housed in a number of museums as well as universities and research institutions [5]. Subsequently, researchers including Michael Mehlman in the late 1970s and early 1980s re-excavated Mumba and other rock-shelters along the Laghangarel-Ishimijega hills. Archaeological records and chronological sequences of Mumba indicate progression in lithic technologies spanning from the
MSA to historic period [18, 21, 23, 24]. The most remarkable discovery are three isolated molar teeth of a single individual who was an early modern human [25]. These human teeth come from the lower sequences of Mumba (Bed VI-B) in direct association with MSA artifacts including Levallois cores, scrapers, points and fossil fauna of extinct and modern species. Amino acid racemization (Lab \# USGS-82-19) indicate that human teeth and oldest MSA assemblage at Mumba, namely the Sanzako industry, spans an age of about 131,000 ya [18, 25].

The Sanzako industry is overlain by the Kisele industry in Bed VI-A. Bed VI-A was found associated with small scrapers, projectile points, Levallois cores and crescents. The bed has been recently dated using Optically Stimulated Luminescence (OSL) (Lab. \# MR 10) to 73,600 $\pm 3,800$ ya. The late MSA culture or the Mumba industry in Bed V is composed of a remarkable array of tips for arrowheads, backed pieces, geometric tools and symbolic artifacts like ochre and ostrich egg shell beads dated by OSL (Lab \# MR 7) around $56,900 \pm 4,800$ ya $[9,26]$. A study on raw material sourcing on obsidian artifacts from the MSA sequences indicate complex mobility and social networks of about $250 \mathrm{~km}$ away linking Mumba and lake Naivasha in Kenya [18, 27]. These findings in the MSA assemblage are vital to better understanding on the origin and development of cognitive thoughts in human evolutionary history. For instance, distance sourcing of obsidian may have granted them essential wider social network, trust and cooperation between a large number of allies and control over the landscape.

At Mumba, the MSA assemblages are chronologically overlain by the Later Stone Age (LSA), which are abundant in Beds III and II. The LSA assemblage is composed of points, backed pieces, bored stone balls, ostrich egg shell beads, land snail shell fragments, a wide range of animal bones and one burial of a single individual OSL dated to about $36,800 \pm 3,400$ ya (Lab \# MR 4) [23, 24]. The LSA layers are superimposed by ceramic LSA (Pastoral 
Neolithic) in upper Bed II and represent the history of transformation from early hunting to animal husbandry around 4,900 ya $[2,18]$. Such continuous cultural records situate the lake Eyasi basin among key sites in the East Africa for documenting the trend for technological and cultural innovations over the course of the MSA and subsequent cultures.

Other important cultural heritage resources of this region include fascinating prehistoric rock art that incorporates drawings of a wide range of wild animals, humans, geometric signs and other objects. Rock-shelters and overhangs with figurative fine-line paintings of wild animals (mostly naturalistic) and stylized human figures. Other ancient visual arts depicted and widely distributed in lake Eyasi basin include abstract and geometric designs. Paintings of humans holding bow and arrows, sometimes shooting at animals indicate that the projectile hunting technology, which is still found among contemporary hunter-gatherer communities like the Hadzabe, has profound history in this region. The Tip Cross-Section Area (TCSA) and microscopic analysis suggest that projectile technology in this region can be traced back to the MSA period [9]. Work is currently underway to reconstruct the chronological integrity and contextualization in broad range archaeological and ethnographical evidence of this region for better understanding of a link between the past and present with reference to the contemporary foraging community.

These paleontological evidences are important to the progression of science, as well as for cultural heritage including tourism developments. Globally, cultural heritage resources are among the most important areas in cultural tourism industry. In most developing countries, the current tourism development strategies are facing serious challenges because many reputable tourism attractions such as archaeological and paleontological sites were not included in initial cultural tourism programmes. In the lake Eyasi basin, even minority groups like Hadzabe have been underprivileged and neglected in the current cultural tourism and development programmes. Such negligence has exposed cultural heritage resources of this region to inadvertent destruction. For instance, cultural heritage sites are facing immense threats from uncontrolled investments including road and lodge constructions, intensive onion farming, deforestations and an influx of migrants from neighbouring communities. Such development and social welfare projects have been deliberately destructing cultural heritage resources and severely harmed the cultural-ecological settings of the Hadzabe people. To assess the level of obliteration of cultural heritage resources, indigenous people, tourist stakeholders and government officials were consulted and their concerns and observations are summarized below.

To understand the perception of local communities, it was decided to integrate them in archaeological survey and test excavations at Mumba and along the lakeshore. The broad goal was to examine the level of awareness among the indigenous people about cultural heritage resources in the region. It also aimed to assess the level of understanding in respect to the potential tourism attractions along the region and evaluate likely threats to their sustainability. The underlying principle was to understand the perceptions of the local communities in the whole process of heritage management, conservation and tourism development. One of the initiatives was to evaluate how information from previous and on-going research has been incorporated into heritage management and socio-economic developments.

An assessment involved seminars, group discussions, interviews and public lectures. The initiatives stimulated public perception on cultural heritage and made them recognize the significance of heritage resources in their area. To reinforce significance of cultural heritage, brochures and posters were prepared and distributed to village offices, primary schools, secondary schools and tour guides. Such an approach smoothed out communication and public dialogue 
about sustainability of previous and newly discovered cultural heritage resources for both scientific and community interests. This approach was first employed in Iringa region, southern Tanzania [13]. This process of information sharing allows the public to raise concerns and gain more knowledge about the importance of cultural heritage resources in their area and make use of them for sustainable developments.

About 112 respondents were interviewed on aspects related to management, conservation and uses of cultural heritage resources in their area for sustainable development. Interview questions focused on the relationship of education and tourism developments with cultural heritage resources and their effect on poverty. The conversation mainly relied on open-ended dialogue and group discussions with key informants, particularly elders and village leaders, tour operators and a few selected individuals from the Hadzabe community. The intention of the open group discussion was to understand the perception of the local communities on cultural heritage management. About 20 key informants including village leaders, tour operators and the Hadzabe, constituting $17.8 \%$ of respondents were interviewed at isolated places to ensure a freedom of expression and secrecy on volunteered information.

\section{Results and Discussion}

The study focused on perception of the indigenous people in heritage management, recognition of heritage legislation, and presence of community-based conservation practices and the rights of minorities (such as the Hadzabe) in the tourism development projects. A total of $74(66.1 \%)$ respondents were well informed about the archaeological research in their area, but said that they had never observed collection of objects including the hominin specimens. This was highlighted as a shortfall of the heritage legislation. Local communities are forbidden from access their heritage assets. About 24 (21.4\%) expressed concern over disengagement of the local community in heritage management and tourism activities. About 14 (12.5\%) of respondents were worried with lack of heritage management knowledge, negligence, misconduct, authoritarian heritage legislation and disincentive development projects in their area.

Specifically, the Hadzabe complained about rapid population influx in their ancestral land, deforestation related to farming, charcoal and poles for housing and threats to wildlife populations. They also complained that an increasing number of pastoralists with their domesticates (cows, sheep and goats) were leading to resource competition with wild animals. The Hadzabe also blamed migrants, including private licensed hunting and farming companies for hunting and reducing number of the big animals such as lions, buffalos and giraffes. Government officials were accused for forcing the Hadzabe community to change their lifestyles and occasionally, arresting them for poaching on land they have traditionally occupied. Non-Hadzabe village officials blamed some tour operators for recently exploit the Hadzabe to keep visitors amused and insensitive fellow residents who provide Hadzabe alcohol to gain money they receives from tourists.

Discussion and seminar presentations affirmed local communities and government officials agreed that their region contains rich and diverse natural and cultural resources with outstanding scientific, aesthetic, economic and historic importance. The cultural resources are valuable not only to Tanzania but also to the international community. Researchers, tourists, religious leaders and donors have been pressing for conservation together with management aimed at long-term sustainability of cultural and natural resources, including the right of minorities such as the Hadzabe [4]. Ecological, cultural and natural assets have significant value for tourism attraction and sustainable conservation. People are aware of the moral responsibility towards sustainable management of cultural resources. However, they are concerned with the current roles played by the government and 
researchers to promote awareness and integrate the local communities in heritage management.

Many people, including tour operators and tourists, were excited to hear about contributions of archaeological sites in this region to the current global knowledge of the origin and dispersal of modern populations. They requested the introduction of outreach programmes to improve awareness among the local communities and tour operators. To them, an understanding of the meaning and significance of cultural heritage resources is not only essential for tourism attraction and economic development, but also can help to protect knowledge by avoiding the inadvertent destruction of heritage resources. Local people felt overlooked in the management and conservation processes and felt that scientists made no effort to tell local people the objectives and significance of their research projects, except for few labourers who carried out casual labours during archaeological surveys and excavations. The majority of the local people never had the opportunity to learn the meaning and significance of collected materials, which leads them to be sceptical that collected materials are needed for reconstruction of cultural history. These misconceptions make it difficult for people to distinguish between professionals and treasure hunters. As a result, some people often start to re-excavate archaeological sites including rock-shelters that were formerly excavated by scientists to assess the authenticity of collected materials (Fig. 2).

Local people also complained about the ambiguity of heritage legislations and policies that provide directives to them through the government heritage agencies. People feel that the government has been spending much time and resources for storage, protection and conservation of museum collections, without considering sustainability of actual sites from which those materials were collected. Such arbitrary and uneven heritage legislations that encourage continued deterioration of potential heritage sites like archaeological/paleontological sites, features and cultural landscapes. Regardless of the outstanding cultural value and scientific contributions of sites like Mumba, most of them are not even listed in the national cultural heritage list. Largely, poor management policies have encouraged local people to establish new settlements and agricultural activities close to heritage sites. The problem is widespread because local government and villages are unaware of the rich cultural heritage preserved in their area. It is maddening to recognize that government heritage agencies continue to provide treasure hunting clearances to unprofessional discoverers without considering the impact of those clearances to cultural heritage resources. Some important rock-shelters with paintings, including Mumba, have been vandalized in various ways including illegally or unprofessionally excavations by treasure hunters or developers by quarrying gravels for road and house construction (Fig. 2).

Mining rock-shelters for construction gravels and treasure hunting are the most common sabotage actions facing cultural heritage sites in Tanzania. During the field survey and documentation of rock art sites in 2009, a large number of archaeological and rock art sites that have been illegally excavated by treasure hunters and developers were recorded. Other detected anthropogenic threats included soot, stain and dust on rock art due to fire and graffiti settingin rock-shelters [13]. Nevertheless, scarcity of trained professionals have made most cultural heritage sites deteriorate from natural courses such as rock-weathering, exfoliation, oxidation and birds as well as hyrax droppings.

This study demonstrates that cultural heritage resources and minority ethnic groups, in particular the Hadzabe are at the forefront of increasing threats more than ever before. This is due to competing interests over land in lake Eyasi basin between farmers, pastoralists and foraging communities on one hand, and financially viable institutions including tour companies and tourists. Farmers want to expand arable 


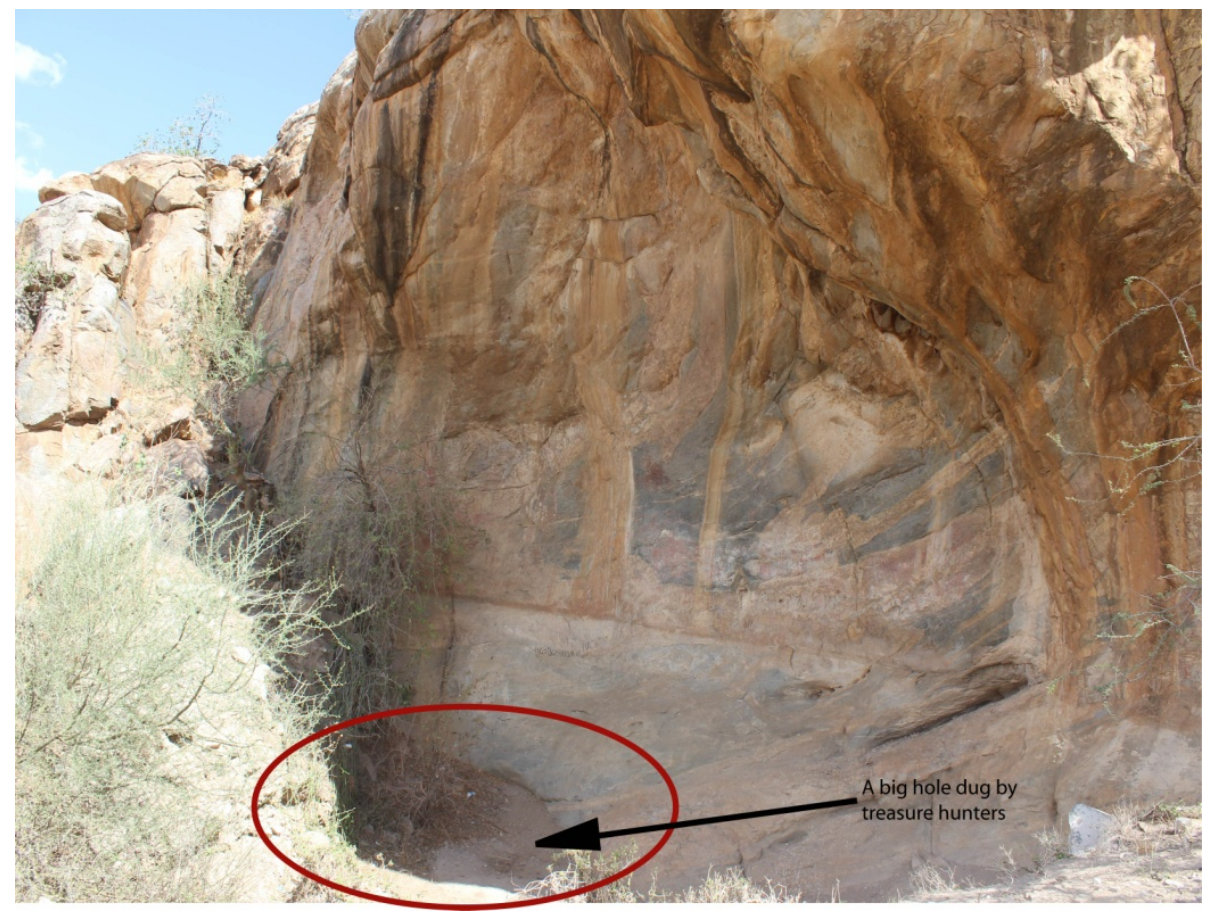

Fig. 3 Mumba rock-shelter indicating big hole dug by treasure hunters.

farms to at least medium size, pastoralists want more land for their livestock, and tour companies want more land for campsites and lodge constructions. These rival groups are lobbying and intimidating not only Hadzabe who have been in this area for over 5,000 years, but also other people who are indigenous to this place [28]. It is distressing to hear that the mission of the local government is to change completely the way of life among Hadzabe by transforming them into communal farming, regardless of the fact that their foraging life-system is the most leading of all tourism temptations in the region [29].

Almost three quarters $(74.1 \%)$ of discussants were well informed about serious ecological threats on the Hadzabeland due to the rapid rate of cutting trees for cleaning new farms, construction of residential buildings, bucolic fuel as well as burning the natural landscape for pastoralism. A total of 82 (73.2\%) of the respondents indicated agricultural activities as the leading factors in ecological devastation. Agricultural development involves intensive irrigation schemes for cropping activities close to water attachment areas and cleaning new farms in areas that were previously unoccupied due to high demand of food to feed the increasing human population in the region, commercial gain and traditional prestige.

Intensification of onion farming was the most highlighted of the damaging agricultural practices because it attracts more casual labourers, farmers and traders from neighbouring communities. Onion cropping has been linked to poor irrigation systems by capturing water from natural springs, which also degrades the environment through soil erosion, vegetation replacements, the decline of natural forests and loss of wild resources. Onion farming was also associated within appropriate uses of industrial fertilizers and pesticides that have deleterious effects on soil fertility and water pollution for cost-effective farming. Often, farmers over-fertilize their farms simply because of unawareness about the specific nutrient content of their soil as well as nutrients required for the intended crops [30]. Excessive uses of fertilizers or pesticides occasionally cause serious damage to aquatic and terrestrial ecosystems because chemical elements tend to integrate into soil or get washed into water bodies. Some of these chemicals 
build up in edible plants and animals, undergoing constant recycling through the bio-magnification process $[3,7]$. When these chemicals finally reach humans at the top of the chain, their levels are usually so highly concentrated such that they constitute serious health and reproductive problems.

As it was argued before, in lake Eyasi, agricultural activities have also been linked with rapid population growth because it attracts non-local labourers and traders. Encroachment on Hadzabeland is largely the result of shifting cultivations of grains to feed newcomers. The need to produce more food in the face of declining soil fertility has been argued among of the reasons for the current infringement of Hadzabeland because farmers are forced either to use industrial fertilizers or extend their farming activities to areas that are ecologically unsuitable for agricultural activities. Such uncontrolled farming activities have been associated with current soil desiccation, erosion, nutrient loss, moisture loss and deprivation of natural resources together with decreased ecosystem productivity. These are among of the leading factors for disappearance of the traditional plant species, which supply foods to Hadzabe. Ecologically, most indigenous tree species do not re-colonize any more after being excessively eradicated [7]. Losses of traditional tree species have great impacts not only on the Hadzabe, but also on all local communities because they are major sources of materials for food stuffs, medicine, firewood and construction materials.

Pastoralism was named the second leading factor for environmental degradation in lake Eyasiby 29 (25.9\%) of the respondents. The ethnic group most commonly engaged in agro-pastoralism is the Datoga people, but new groups including Maasai are also migrating to the region. An excesses number of domesticates tend to displace wildlife and disrupt consumption of plant species, posing serious threats to the Hadzabe way of life. Invasive domesticates inhibit species diversity and bring about permanent replacement of natural occurring biota as pastoralists often remove trees from grazing lands in order to increase the growth of grass [ 5 , 31]. Decreasing woodland and expansion of grassland have been linked to the increased need for firewood, charcoal and building materials because of rapid expansion of Mang'ola town and the influx of fishers at the end of rainy seasons when the lake level is at the highest state. Fishers make use of trees to burn fish products and also for constructing seasonal fishing sites. Even though it has been repeatedly argued that local people collect only dead wood of selected species to satisfy their fuel requirements [31], experience from lake Eyasi indicated that in high seasons, people gather even living trees. Loss of trees has been argued to cause significant impacts on wildlife resources because of increasing destruction of animal habitats. Conclusively, deterioration of Hadzabe's cultural landscape is due to a combination of factors including high rate of population growth, poor land management plan and uncontrolled irrigation together with shifting cultivation as well as poaching. They are all causing a massive destruction of wildlife habitats, the condition that also threats sustainability of the Hadzabe because their life largely depends on the wildlife resources.

Drawing from the discourse with local community, tour operators and local government officials, it is obvious that there are several obstacles to heritage management in the Eyasi basin. Dominant problems impeding heritage management in this area include lack of knowledge about the importance of heritage sustainability, environmental degradation and competition over land and other natural resources.

One way of reducing degradation of these irreplaceable heritage resources is to stop excessive exploitation and restrain settlements close to the inherited properties through a combination of community outreach and law enforcement. Community outreach should form the greater part of the effort and law enforcement should be a last resort, only used when there is assured continued devastation of the heritage resources [1]. Outreach programs should involve all stakeholders including indigenous people, 
local government officials and tourism practitioners. Special emphasis should be directed on sympathetic understanding about the meaning, importance, uses, protection, management and conservation of cultural resources for sustainable developments [13]. In the case of Mumba and other similar sites, the long-term strategy should be to add such sites to the national heritage list and establish local museums to exhibit collections from these sites. To express authenticity of the local communities, archaeological records should be supported by ethnographic objects and exhibited in the site museum. This must involve collaboration between national bodies, heritage agencies and local communities.

In Tanzania, the Department of Antiquities and National Museums of Tanzania are national institutions responsible for management and conservation of cultural heritage resources, under the Ministry of Natural Resources and Tourism. The Department of Antiquities is charged with management and conservation of immovable, movable and research undertakings, while the National Museums of Tanzania is responsible for movable cultural heritage stored in museums [32]. The Antiquities Act of Tanzania enacted by the independent government in 1964 and amended in 1979 is the basic legislation for management, protection and preservation of heritage sites and other cultural resources. It was designed to replace the colonial Monument Preservation Ordinance of 1937 developed by British colonialists to protect and preserve movable and immovable heritage resources [13]. The Act protects all relics that were made, shaped, carved, inscribed, produced or modified by humans before 1863. The Act also protects all monuments (buildings, structures, paintings, carvings, entombments and earthworks) made or used by humans before the year 1940. The Act gives the Director of Antiquities the power to regulate, supervise and control tangible or physical cultural heritage resources together with research undertakings [32]. It also gives the responsible minister immense powers to declare any area, object or structure, a monument or conservation area as a heritage site. Unfortunately, the act does not recognize the local community as partners in a sustainable cultural heritage management for the country [13].

To a great extent, the current challenges facing the cultural heritage management sectors in Tanzania stem from the colonial Monument Preservation Ordinance of 1937. The colonial legislation was meant to serve interests of colonialists, a condition that causes subsequent legislation ignore public interests including customary rights and traditional rules [13]. Most African legal frameworks for protection and conservation were enacted from colonial legislations that neglect the right and interests of general public to inherit, manage and protect their cultural resources [5, $14,32,33]$. These inherited colonial legal systems have continuously disregarded customary laws and indigenous knowledge. As a result, most current heritage legislations in Africa cannot provide for the kind of inclusive approach that would allow and address community interests for sustainable utilization of heritage resources so as to make progress in socio-economic development [13, 34]. Such negligence and marginalization of the public have created a political context in which the local communities have lost a sense of responsibility for heritage management. As a result, they have been unevenly invading heritage sites and often mining them for domestic uses. Therefore, the Antiquities Act and allied legislations as well as policies should be harmonized and amended to include the local communities in heritage management. The condition may make the public proactive in enhancing and ensuring long-term preservation of cultural heritage resources in Tanzania.

On the other hand, the Department of Antiquities has been incessantly blamed for mismanagement of cultural heritage resources. Stakeholders of cultural heritage have been repeatedly asking the Department of Antiquities to stop issuing treasure hunting 
clearances because treasure hunters have damaged cultural and natural heritage sites, in particular, rock-shelters [1, 15]. In lake Eyasi, dishonourable excavations in archaeological sites are wide occurrences in rock-shelters across the Laghangarel-Ishimijega hills. The continued granting treasure hunting clearances maybe explained as a result of imperfection of conservation laws and legislations that refute rights of local people to protect and conserve their heritage resources, or as the result of ignorance of the local communities about their cultural history $[5,12$, 13].

Addressing the problem of environmental dispute and rights of minority groups (Hadzabe), especially at the local government level requires proper education about human rights and its applications in serving the interests of marginalized groups. The most serious challenge facing the Hadzabe is an effect arising from on-going environmental degradations that have significantly affected reliability and distribution of wild food resources. These wild resources constitute their daily sustenance. Both traditional customs and law enforcements should be imposed so as to restrict the current deforestations and uncontrolled farming including shifting cultivations, harmful uses of pesticides and fertilizers as well as unskilled farming in the river catchments. These deceitful anthropogenic practices have led to siltation which reduces the quality of water sources and harms plant and animal species [7, 31]. The current environmental devastation has put the Hadzabe's life and cultural traits at great risk. Apart from ecological desertification, other challenges facing them include negligence of local government officials, exploitative tourism practice, unmonitored hunting companies and lack of moral as well as legal obligations permitted to serve interests of the minority groups. Despite the fact that the Hadzabe plays a major role in the tourism industry of lake Eyasi, this community has never been appreciated or privileged as one of major tourism stakeholders. The energy and time they spend to keep visitors amused are not proportional to the remunerations they earn from tourism companies.

Globally, the United Nations Education, Science and Cultural Organization (UNESCO) has been one of the leading agencies in preparing and adopting conventions on management and conservation of natural and cultural properties as well as safeguarding the rights of local communities. Some of these conversions include the 1954 Hague convention for protection of cultural property in the event of conflicts, the 1972 convention on world cultural and natural heritage and Agenda 21 of 1992 about the role of local communities in heritage management, environmental and development projects $[11,35]$. The 1992 declaration requires states to recognize and duly support identity, culture and interests of local communities, which enable them to participate effectively in achievements of sustainable developments. The UNESCO conventions were reinforced through actions and endorsements made by other international organizations such as the World Bank (WB), World Trade Organization (WTO), Environmental and Development Activities (ENDA) and Food and Agricultural Organization (FAO), just to list a few.

In 1998, the WB in collaboration with UNESCO and WTO declared that among the assessment criteria for development projects in developing countries and post-conflict areas, there will be assessments of environmental and cultural impacts and the ways in which local communities have been integrated in the development projects $[11,36]$. In 2103, FAO proposed measures to combat deforestation by initiating and publicizing community management of natural forests in the course of tree growing programs and uses of improved biomass stoves [37]. The mismanagement of natural forests was influenced by weak and slow-changing heritage institutions, inconsistent laws and regulations as well as a cumbersome bureaucracy in heritage management $[12,36]$. To a great extent, these international conventions and declarations 
address the needs for protection of natural and cultural heritages and emphasize the incorporation of local communities during implementation of development and heritage management projects [13]. A small amount of these international declarations received full government endorsement and they have made positive contributions to the local communities by allowing them to participate in different levels of decision-making. However, in most cases, states issued ambiguous and general directives pertaining to development and socio-economic practices, excluding local communities [38].

Integration and uses of heritage resources for sustainable development by some means are held back by deficiency of heritage and tourism professionals who can collaborate with the local people. Lack of trained cultural tourism specialists has remarkably influenced disgraceful decisions made by the national heritage and tourism agencies. Such state of affair also affects marketability of cultural heritage properties in tourism industry. Both the Tanzania Tourist Board (TTB) and the Department of Tourism, Ministry of Natural Resources and Tourism, Tanzania, lack trained staff specialized in archaeological, paleontological or cultural heritage tourism disciplines necessary for consistent plans for incorporating cultural heritage properties into the tourism mercantile networks. Unfortunately, some of the local universities have recently introduced such programmes at certificate, diploma and degree levels for personnel who may run over advocated under performance in heritage management and cultural tourism practitioners. However, it is strongly advised that local universities should also introduce a Post-Graduate Diploma (PGD) to train graduates who are currently working in tourism and heritage management sectors, but lack basic technical and professional skills. Training staffs that in essence deal with activities of tourism as well as environmental, natural and cultural heritage managements would greatly improve management and uses of inherited resources in Tanzania.

\section{Conclusion}

The current challenge facing cultural tourism industry in lake Eyasi basin can be directly associated with lack of awareness of cultural heritage resources, marginalization of minority groups and ecological degradations. Ambiguous programmes and uneven implementation of heritage management policies have contributed to the problem. The current regime does not consider the rights and moral obligations of local communities to determine the fate of their own culture. These legislative discrepancies coincide with on-going negligence and inattention of cultural heritage resources, environmental degradations, and unsustainable land use plans in lake Eyasi basin.

The current situation facing Hadzabe foragers as a community demonstrates the need for harmonized heritage and land management policies including legislations that may persuade dishonourable conservation of cultural properties and avoid environmental degradations. This can only be achieved by changing the authoritarian legal practices that deny the rights and obligations of local people to determine their fortune in heritage practices. Thus, environmental and heritage management campaigns are likely to be more effective if they are based on equality among stakeholders involved at different levels. Under such situation, the government should make sincere efforts to save interests of minority groups by sharing profit occurred with them in relative to moral obligation and cost-effective contributions. If the communities are involved in heritage management and dividends from tourism projects are equally shared, it is likely that protection and conservation of intended resources will be highly effective and sustainable. Mistrust among stakeholders can become a significant drawback to conservation practices and tourism developments if legal practices are deceitful and not reciprocally agreed. Thus, poor institutional arrangements may depress interests and willingness of other stakeholders to play their parts in heritage management. 
It is evident from this study that community understanding of the meaning and uses of cultural heritage resources is under developed. This can be rectified through various sensitization programs such as community outreach, community based heritage management, joint heritage management and conservation and collaborative heritage management. New policies should emphasize participatory heritage management and conservation so as to give chance to local communities to learn, understand and get involved in heritage management at different levels. Local people should be educated on how to incorporate cultural attractions into tourism for sustainable heritage management and developments. Such practice would lead to effective management strategies in contrast to current streamlined and authoritarian cultural heritage legislations. Uncoordinated strategies in heritage management and tourism development may be a core for inefficiencies conflicts between conservation and development programs.

Integrating local people as an essential part of administration of heritage resources at least at the grassroots levels would greatly reduce unintended destruction of cultural heritage resources and improve working relations as well as corporations between the government and the public. It is likely that cultural heritage management and development plans in lake Eyasi could have been far different today if public awareness and community participation could have been accepted as well as incorporated in heritage legislations and policies. To avoid resource abuse, some authoritative legislation should be amended and harmonized. They should emphasize on decentralization and public participation in heritage management. State heritage and tourism practitioners should dedicate a small percentage of tourist incomes to support the local communities, in particular, minority groups such as the Hadzabe in order to reduce poverty all around. Some resources should be dedicated to education and support on conservation and sustainable utilization of cultural heritage resources.

\section{Acknowledgements}

Sincerely thank should go to the Volkswagen Stiftung Foundation Initiative: Knowledge for Tomorrow Cooperative Research Project in sub-Saharan Africa through a Postdoctoral Fellowship in Humanities in sub-Saharan and northern Africa for funding this study. Thanks are also due to the Antiquities Department, Ministry of Natural Resources and Tourism and the Tanzania, Commission of Science and Technology (COSTECH), Tanzania for granting research clearance and permits. In the field, more support was from the village government and local people, their contribution is highly appreciated. Lastly, the participation of Prof. Audax Mabulla, graduate students and research assistants was of great importance.

\section{References}

[1] Mabulla, Z. P., and Bower, J. 2010. "Cultural Heritage Management in Tanzanian's Protected Areas: Challenges and Future Prospects." The Journal of Heritage Stewardship 7: 27-45.

[2] Ebinger, C., Poudjom, Y., Mbede, E. A., and Dawson, J. B. 1997. "Rifting Archaean Lithosphere: The Eyasi-Manyara-Natron Rifts." Journal of the Geological Society 154: 947-960.

[3] Domínguez-Rodrigo, M., Diez-Martín, F., Mabulla, A., Luque, L., Alcalá, L., and Tarriño, A. et al. 2107. "The Archaeology of the Middle Pleistocene Deposits of Lake Eyasi (Tanzania)." Journal of African Archaeology 5 (1): 47-78.

[4] Marlowe, F. W. 2010. The Hadza Hunter-Gathers of Tanzania. Los Angeles: University of California Press.

[5] Munjeri, D. 2005. "Legislation and Practices: Implications and the Way Forward." In Legal Framework for the Protected of Immovable Cultural Heritage in Africa, edited by Ndoro, N., and Pwiti, G. Dakar: ICCROME.

[6] Rafalski, S., Schröter, P., and Wagner, E. 1978. "The Finds on Eyasi Northeastern Shore." In the Archeological and Anthropological Results of Expeditions in Northern Tanzania, edited by Miiller H. B. Tübingen: Monograph of Prehistory.

[7] Mannion, A. M. 1995. Agriculture and Environmental Change: Temporal and Spatial Dimension. Chichester: John Wiley and Sons Ltd.. 
[8] Mapunda, B. B. B. 2005. "Cultural Heritage and Development in Tanzania." In Salvaging Tanzania's Cultural Heritage, edited by Mapunda, B. B. B., and Msemwa, P. Dar es Salaam: Dar es Salaam University Press.

[9] Bushozi, P. G. M. 2011. "Lithic Technology and Hunting Behaviour in the Middle Stone Age (MSA) of Northern and Southern Tanzania." Ph.D. thesis, University of Alberta.

[10] Cohen, A. S., Stone, J. R., Beuning, K. R. M., Park, L. E., Reinthal, P. N., and Christopher, D. D. et al. 2007. "Ecological Consequences of Early Late Pleistocene Megadroughts in Tropical Africa." Proceedings of the National Academy of Sciences 104 (42): 16422-16427.

[11] Segobye, A. 2007. "The Gods are Resting There: Challenges to the Protection of Heritage Sites through Legislation and Local Knowledge." In Indigenous Knowledge Systems and Intellectual Property in the Twenty-First Century, Perspective from South Africa, edited by Mazonde, I., and Thomas, P. Africa: CODESRIA.

[12] Shiner, L. 1994. "Primitive Fakes, Tourist Art, and the Ideology of Authenticity." The Journal of Aesthetics and Art Criticism 52 (2): 225-234.

[13] Bushozi, G. M. 2114. "Towards Sustainable Cultural Heritage Management in Tanzania: A Case Study of Kalenga and Mlambalasi Sites in Iringa, Southern Tanzania. South African Archaeological Bulletin." 69 (210): 136-141.

[14] Skeates, R. 2010. Debating the Archaeological Heritage. London: Duckworth.

[15] Itambu, M. P. and Bushozi, P. G. M. 2015. "The Rock-Art of Iringa, Southern Tanzania." Journal of African Archaeological Network 12: 156-181.

[16] Kohl-Larsen. 1943. On the Trial of Prehistoric Man. Stuttgart: Strecker und Schröder.

[17] Kohl-Larsen, L., and Kohl-Larsen, M. 1957. The Pictures Stress East Africa. Kassel: Erich Roth Verlag.

[18] Mehlman, M. 1989. "Later Quaternary Archaeological Sequences in Northern Tanzania." Ph.D. thesis, University of Illinois.

[19] Woodburn, J. W. 1970. Hunters and Gatherers: The Material Culture of the Nomadic Hadza. London: Trustees of the British Museum.

[20] Conard, C. 2012. World Heritage and Middle Stone Age: Examples from East and South Africa. In Human Origin Sites and the World Heritage Sites, edited by Sauz, N. Paris: UNESCO.

[21] Prendergast, M. E., Luque, L., Dominguez-Rodrigo, M., Martin, F. D., Mabulla, A. Z., and Barba, R. 2007. "New Excavation at Mumba Rock-Shelter, Tanzania.” Journal of African Archaeology 5 (2): 217-243.

[22] Domínguez-Rodrigo, M., Mabulla, A., Luque, L., Thomson, K., Rink, J., and Diez-Martín, F. et al. 2008. "A New Archaic Homo Sapiens Fossil from Lake Eyasi, Tanzania." Journal of Human Evolution 54: 899-903.

[23] Díez-Martín, F., Domínguez-Rodrigo, M., Sánchez, P., Mabulla, A., Tarriño, A., and Barba, R. et al. 2009. "The Middle to Later Stone Age Technological Transition in East Africa, New Data from Mumba Rockshelter Bed V (Tanzania) and Their Implications for the Origin of Modern Human Behavior." Journal of African Archaeology 7 (2): 147-173.

[24] Gliganic, L. A., Jacobs, Z., Roberts, R. G., Dominguez-Rodrigo, M., and Mabulla, A. Z. P. 2012. "New Ages for the Middle and Late Stone Age Deposits at Mumba Rockshelter, Tanzania: Optically Stimulated Luminescence Dating on Quartz and Fieldspar Grains." Journal of Human Evolution 62: 533-547.

[25] Bräuer, G., and Mehlman, M. 1988. "A Hominid Molar from a Middle Stone Age level at Mumba Rock-Shelter, Tanzania." American Journal of Physical Anthropology 75: 69-76.

[26] Marks, A. E. and Conard, N. J. 2008. "Technology vs. Typology: The Case for and against a Transition from the MSA to the LSA at Mumba Cave." In Proceedings of Commission 65, XV Congress of the U.I.S.P.P., 13-131.

[27] Merrick, V. H., and Brown, F. H. 1984. "Obsidian Sources and Patterns of Resource Utilization in Kenya and Northern Tanzania: Some Initial Findings." African Archaeological Review 2: 129-152.

[28] NCAA. 2013. Ngorongoro Conservation Area Authority Tourism Status in the NCA. The United Republic of Tanzania: The National Tourism Policy.

[29] Mabulla, A. Z. P. 2007. "Hunting and Foraging in the Eyasi Basin, Northern Tanzania: Past, Present and Future Prospectus." African Archaeological Review 24: 15-33.

[30] Cunningham, W. P., Saigo, B. W., and Cunningham, M. A. 2003. Environmental Science: A Global Concern. New York: McGraw-Hill.

[31] Nhamo, G., and Inyang, E. 2011. Framework and Tools for Environmental Management in Africa. Dakar: CODESRIA.

[32] Kamamba, D. 2005. "Cultural Heritage legislation in Tanzania." In Legal Framework for the Protected of Immovable Cultural Heritage in Africa, edited by Ndoro, N., and Pwiti, G. Rome: ICCROME.

[33] Musiba, C. 2012. "Negotiating Conservation and Sustainable Use of Tanzania's Paleo Anthropological Heritage: The Laetoli Hominin Footprint Site in Ngorongoro, Northern Tanzania." Presented at First International Conference on Best Practices in World Heritage. 
[34] Nègri, V. 2005. "An Overview of Formal Legislation on Immovable Cultural Heritage in Africa." In Legal Framework for the Protected of Immovable Cultural Heritage in Africa, edited by Ndoro, N., and Pwiti, G. Dakar: ICCROME.

[35] Keitumetse, S. G., and Matlapeng Monamo, L. 2007. "Cultural Landscape and World Heritage: In Pursuit of the Local in the Tsodilo Hills, Botswana." In Series of
World Archaeological Congress: Situations and Standpoint in Archaeology and Heritage, 101-117.

[36] UNESCO, 1998. World Heritage Document. Paris: UNESCO Publication.

[37] FAO. 2003. State of the World Forests. Rome: Food and Agriculture Organization.

[38] Maturo, E. 2012. Tanzania Cultural Tourism (5). Arusha: Tanzania Tourist Board. 